though running through there is an appreciation of the direct relationship of the work done to human and animal disease. Other papers deal directly with host parasite relationship in particular the tissue reactions.

For anyone interested in this field there is here an opportunity to judge not only the results of the current researches but also the qualities of mind of the men responsible for them.

\section{ANTIMETABOLITES AND CANCER}

Edited by Cornelius P. RhoAds. Pp. vi +3 I2, with 50 illustrations. Washington: American Association for the Advancement of Science. $1955 \$ 5.75$

About ten years ago it was shown that sulphonamides kill bacteria because their structural resemblance to Para-amino baezoic acid enables them to enter-instead of PAB - into chemical processes which normally lead to the formation of folic acid but would not be completed with sulphonamides as a substitute. This antimetabolic action is fatal to bacteria because they cannot assimilate folic acid from outside.

Since then many substances have been tried empirically for their ability to interfere with the metabolism of malignant cells but at present there are only a few which are clinically useful, i.e. Aminopterin and 6-Mercaptopurine in acute leukaemia. The ideal is, of course, to find some essential metabolitic process which is characteristic for a malignant cell and then to construct an antimetabolite for it.

The symposium deals mainly with the general aspects and with laboratory research but there is one chapter on the present status of antimetabolites in the treatment of acute leukaemia.

\section{DISEASES OF THE NERVOUS SYSTEM}

By Sir Russell Brain, Bt., D.M., F.R.C.P. 5th

Edition. Pp. xviii +996 with 90 illustrations.

London: Geoffrey Cumberlege, Oxford University Press. $1955.55 \mathrm{~s}$.

This book has proved itself a valuable aid to anyone interested in Neurology and the clarity of its presentation has done much to dispel the confusion that tends to surround this subject in the minds of both under-graduate and post-graduate students.

The justifiable need for a new edition so soon after the last is testimony to the steady advance of this speciality in all its fields. The general formation of the book has not been altered. It starts with a chapter on relevant anatomical and physiological subjects so necessary before considering any neurological disease. The following sections on the various pathological states which may affect the central and peripheral nervous systems are each accompanied by a short bibliography giving the student an easy reference to original work on any subject in which he is particularly interested.
In this edition there is new material on cervical spondylosis, a condition which has to be considered so often in the differential diagnosis of spinal cord disease. Additional information is also given on the Coxsackie viruses and on subacute sclerosing leuco-encephalitis which may be an encephalitis of virus origin although this is not yet proven.

A section on acute haemorrhagic leuco-encephalitis is added to the chapter on demyelinating diseases of the nervous system and the neuropathies and myelopathies associated with carcinoma are now dealt with in a new chapter.

The interesting similarities between polymyositis and muscular dystrophy are reviewed as well as the nervous complications of toxoplasmosis.

Further information has been added on recent advances in the treatment of the various types of meningitis, of poliomyelitis and of lead poisoning.

One small criticism that might be made is the lack of a separate discussion of epileptic fits arising from the temporal lobes in the absence of any progressive lesion; apparently such a common cause of epilepsy among adults. However, this book is an up to date and comprehensive review of Neurology and the new edition enhances its already wellestablished reputation.

N.S.G.

\section{ANTIBIOTIC MONOGRAPHS 4 ANTIBIOTICS IN NUTRITION}

By Thomas H. Jukes, Ph.D. Pp. I28. New York: Interscience Publishers Inc. 1955. \$4.00.

This monograph sets out to record the results of feeding antibiotics to animals and to children. It is too superficial to appeal to the scientific worker interested in fundamental research and too complicated in presentation for the average farmer or farm worker in this country.

The lay out gives the usual impression of a scientific paper, the standard system of references to the various relevant publications is followed, but the impression left is one of vagueness. The relative merits of the papers discussed is insufficiently stressed and no clear picture of the mode of action of these food supplements emerges.

W.H.H.

\section{AN ATLAS OF REGIONAL DERMATOLOGY}

By G. H. Percival, M.D., Ph.D., F.R.C.P.E., D.P.H., and T. C. DoDDs, F.I.M.L.T., F.I.B.P., F.R.P.S. Pp. vii +264 . Edinburgh: E. \& S. Livingstone Ltd. I955. £5.

This colour atlas of skin diseases would be very good value, even if there many fewer illustrations. Then perhaps the pictures could be larger, for at present they are too small to show clearly the finer details of the lesions on which the diagnosis may depend.

It is not quite clear for whom the book is intended. The preface tells us that 'its scope is limited to the 
presentation of representative examples of the common and less rare cutaneous disorders', so that the inclusion of Lupus Erythematosus Profunda and Angiokeratoma Corporis Diffusum, together with other rarities, is surprising.

This will be a useful reference book for those many Doctors who are occasionally faced with a dermatological problem and wish to be reminded of the appearance of an eruption which they have seen in the past, though the student will soon find that it is impossible to learn the characteristics of skin diseases from pictures alone.

Let us hope that in the next edition there will be a thorough pruning of the obscurities and enlargement of the remainder, when this will be a very useful book.

\section{R.G.H.}

\section{BODY FLUIDS IN SURGERY}

By A. W. Wilkinson, Ch.M., F.R.C.S.E. Pp. ix + 212. Edinburgh: E. \& S. Livingstone Ltd. 1955. I6s.

This book is the latest recruit to a select group of monographs on fluid and electrolyte topics which has been published in recent years. As announced in the preface, it is an attempt to provide the average practising surgeon with the basic knowledge concerning the physiology and pathology of the body fluids, together with some hints as to the management of different clinical disturbances.

In a work of this type it is a pity, perhaps, that the author has so frequently referred to hypothetical explanations for various mechanisms rather than being content with stating the observed facts. Many physiologists, for example, would have cause to disagree with his interpretation of the thirst mechanism and its functional significance and perhaps, also, it is not in the ultimate interests of truth to perpetrate the simplified definition of acidosis as 'confined to the states in which the plasma bicarbonate or alkali reserve is diminished.'

The chapters on clinical disturbances are good and up to date and, with the exception of a figure in the table of therapeutic solutions, accurate. Many surgeons will find this book useful and it. can be recommended to students.

\section{B.J.H.}

\section{THE BRITISH JOURNAL OF TUBERCULOSIS AND DISEASES OF THE CHEST \\ Golden Jubilee}

It is now exactly fifty years since this Journal commenced publication and the January number of 1956 is a special Golden Jubilee issue. This Journal maintains a very high standard and can be strongly recommended to all postgraduates who are interested in this great branch of medicine.

Originally primarily a Journal for tuberculosis only, it has gradually enlarged in scope with the rapid development of other branches of chest medicine and surgery. With the decrease in the incidence of pulmonary tuberculosis which is so well commented upon in the editorial it becomes apparent that, due to the successful efforts of those in charge of these patients, it may perhaps be wise at some future date to change the title of this Journal possibly by simply reversing it to the British Journal of Diseases of the Chest a $\mathrm{Bd}$ Tuberculosis because surely in the very near future diseases of the chest as a whole are going to become more important than palmonary tuberculosis.

The Editors, not only of today but also of the past fifty years, are to be congratulated on this fime Jubilee number and also on maintaining suchōa high standard over the years.

\section{POLYCYTHEMIA}

By John H. LaWrence, M.D., D.Sc., F.A.C.P. Pp. viii $+{ }_{136}$, with 38 illustrations. Londom: Grune and Stratton. 1955. \$5.50.

Dr. J. H. Lawrence is the director of the Donnis Laboratory at Berkeley, California, and is we ll known for his work on isotopes and on polyocythemia. Many of his assistants also have maghe valuable contributions on the same topics.

This short text is No. I 3 of a series of modesh medical monographs. It is divided into 3 main parts. A distinction is made between po:cythemia vera and relative and secondary types of polycythemia. The colour frontispiece is a goot attempt, unfortunately not well reproduced, $\mathbf{E}_{0}$ show the difference between polycythemia aff erythrocytosis (as many haematologists prefer $\stackrel{\text { PO }}{0}$ call this symptomatic state). The author an 8 hits associates have made clinical, physiological, netger bolic and therapeutic studies on 231 patients 가t polycythemia vera. This is a very large sertes considering that polycythemia is even rarer then leukaemia. In $7 \%$ of cases there was a family history of blood dyscrasias. The size of the spleftn varies greatly in different cases, but there is definite direct relationship between size of spleen and number of white cells in the blood. Tiss confirms the findings not usually appreciated, that polycythemia is a panmyelopathy involving leucopoiesis and megakaryocytopoiesis as well as erythropoiesis in hyperplasia. The abnormal iron metabolism in polycythemia is related to increased rêd cell production, a shortened life of red cells a $\overline{\text { ad }}$ extramedullary haemopoiesis. Treated with radoactive isotopes, particularly $\mathrm{P}^{32}$, haemotalogigal remission was achieved in $94 \%$ of cases, but $\overline{7} 3$ patients died, of these 16 with leukaemia.

Dr. Lawrence also gives a short account of his experiences in the study of polycythemia at hish altitudes carried out in Peru, at an altitude $\mathrm{gf}$ r6,000 feet. There the blood showed haemocolscentration, but no splenomegaly, leucocytosis -or thrombocythemia. Throughout the text reptosentative case histories are given and there çs another batch in an appendix, sometimes made on the form of a graph. The list of over 200 references includes classical and newer papers on potycythemia. It has a catholic range, but is neither arranged by alphabet or by publication date $\overrightarrow{\mathrm{p}^{r}}$ subject. 